artelogie

\section{Artelogie}

Recherche sur les arts, le patrimoine et la littérature de l'Amérique latine

$8 \mid 2016$

Transgression dans les arts / transgression des arts

\title{
Transgressão das artes/Transgressão nas artes
}

Gaspar Paz, Aline Miklos, Olgária Matos e Dominique Chateau

\section{OpenEdition \\ Journals}

\section{Edição electrónica}

URL: http://journals.openedition.org/artelogie/623

DOI: 10.4000/artelogie.623

ISSN: 2115-6395

Editora

Association ESCAL

\section{Refêrencia eletrónica}

Gaspar Paz, Aline Miklos, Olgária Matos e Dominique Chateau, «Transgressão das artes/

Transgressão nas artes », Artelogie [Online], 8 | 2016, posto online no dia 26 janeiro 2016, consultado o

10 dezembro 2020. URL : http://journals.openedition.org/artelogie/623 ; DOI : https://doi.org/

10.4000/artelogie.623

Este documento foi criado de forma automática no dia 10 dezembro 2020.

Association ESCAL 


\title{
Transgressão das artes/ Transgressão nas artes
}

\author{
Gaspar Paz, Aline Miklos, Olgária Matos e Dominique Chateau
}

Gostaríamos de agradecer imensamente a toda equipe de Artelogie, em especial a Edgard Vidal que sempre foi muito solicito e atencioso conosco. Nosso imenso agradecimento também para Cristina Moura, que traduziu os textos de Dominique Chateau e Raoul Kirchmayr para o português, e a todos os pareceristas que nos ajudaram a avaliar e selecionar os textos aqui publicados. São eles :

Adilson Florentino (UNIRIO), Aline Prúcoli (UFES), Amélia Siegel Corrêa (UFPR), André Queiroz (UFF), Camila Bechelany (EHESS), Camila Maroja (Brown University), Carine Lemouneau (Paris 1- Sorbonne), Carolina Amaral (USP), Christine Frerot (EHESS), David Ruiz Torres (UFES), Eduardo Dimitrov (UNB), Ignacio del Valle Dávila (UNICAMP) Lilian Santiago (UNIFESP), Mara Burkart (CONICET-UBA), Matías Allende Contador (Museo de Arte Contemporáneo de la Universidad de Chile), Mônica Zielinsky (UFRGS), Ricardo Fabbrini (USP), Rosângela de Jesus (UNILA), Tânia Navarro Swain (UNB), Tiago Barros (IFRJ), Tiago Machado de Jesus (USP), Vincenzo Cambria (UNIRIO).

1 São representativas na história da arte latino-americana as tensões entre a norma e a contravenção, a moralidade e a imoralidade, o clássico e o popular, o oficial e o extraoficial, o Novo e o Velho Mundo. Neste jogo de forças, observamos que a transgressão emerge de uma espécie de saturação diante de situações-limite, visto que a ação de transgredir põe em cena o extravasamento das relações, seja mediante um ímpeto novo de imaginação e criatividade, seja pela suspensão dos acontecimentos. Assim, a ideia de transgressão pode ser considerada como impulso de transformação em situações variadas, já que reacende o espírito crítico através daquilo que Blanchot chamou de princípio de contestação ${ }^{1}$ e que se define como um esforço de pensar e agir de um modo outro.

2 Nas artes, tais atitudes foram vivenciadas por meio da crítica à normatividade, à hierarquia dos valores e à interdição; bem como pela constatação dos limites de nossa própria linguagem ${ }^{2}$. Nessa linha, observamos o aparecimento de obras que perpassaram ao menos três formas transgressivas : a arte que ultrapassa as regras da arte, a arte que 
destrói os tabus e a arte de resistência política. Na América Latina, o encontro entre diversas culturas gerou, no que concerne às artes e às expressões culturais, um processo de mestiçagem e hibridização das formas. Estes eventos, marcados pela violência e por circunstâncias conflitantes de imposição/resistência e submissão/ transgressão, são também reflexos dos confrontos que ocorreram durante o período da colonização. Nesse sentido, tais relações se caracterizaram pela aceitação, o rechaço e a incorporação de novos elementos que impulsionaram sincretismos. A partir desse ponto de vista, a transgressão pode ser considerada como fruto desses conflitos, principalmente quando relacionada com o processo de mestiçagem e com questões políticas ou morais. Como exemplo, poderíamos citar as inúmeras polêmicas em torno da representação de Virgens com traços mestiços ou a pintura A Carioca de Pedro Américo, que no final do século XIX, causou grandes discussões devido a seu grau de erotismo.

3 No século XIX, em decorrência da criação das primeiras academias de arte na América Latina, os conflitos entre arte oficial e arte popular, tradição clássica e estilos modernos se acirraram e se somaram ao aparecimento de obras de caráter irônico e caricaturas subversivas. Essa relação entre Velho e Novo mundo não cessou com a independência das colônias e se expressa nas artes latino-americanas até o final do século XIX e princípio do século $\mathrm{XX}$, com o advento das vanguardas históricas. Tais movimentos eram movidos pelo desejo de transvaloração dos valores estéticos e éticos, através do rompimento com o classicismo e com a hegemonia da política colonialista. Nessa perspectiva, a transgressão se torna uma das vias propulsoras de movimentos artísticos como o muralismo no México, o modernismo brasileiro ou o Grupo Minorista cubano da década de 1920.

4 Se na primeira metade do século XX a transgressão expressava, principalmente, anseios transformadores, posteriormente sua presença se intensifica nas manifestações contemporâneas, cujos imperativos de singularidade e autenticidade incitam grande parte dos artistas a adotar a transgressão como postura indissociável à produção artística. Em muitos países latino-americanos, os anos 1960 e 1970 foram representativos neste sentido, com o surgimento da arte conceitual, do neoconcretismo e da arte experimental. Somando-se às transformações estéticas, às contestações políticas e morais, observamos ainda o aparecimento de obras que, com o objetivo de intervir na própria realidade, procuraram desafiar as fronteiras entre realidade e ficção, ou mesmo questionar a relação do corpo com os padrões morais, como as obras de Batato Barea (Argentina), Mónica Mayer (México) e Enrique Lihn (Chile). Seus protagonistas buscaram se subverter das coerções que regem não apenas áreas artísticas específicas, mas que estão presentes no todo da vida cotidiana : nos padrões sexuais, nas morais religiosas, nas relações de gênero, nos hábitos de comportamento, nas formas de relacionamento, nos contrastes econômicos, políticos e ideológicos. Esses atos transgressivos na arte contemporânea suscitaram pelo menos dois tipos de contrapartida : a incorporação e a censura.

5 No primeiro caso, a necessidade de reagir perante a contravenção produziu, segundo Nathalie Heinich, o grande paradoxo contemporâneo : quanto mais os artistas desafiam as fronteiras dos museus, do direito, da moral e da autonomia, mais as instituições ampliam suas fronteiras para que esse tipo de arte seja incorporado (HEINICH, 2006). Devido a essa necessidade de aceitação (por parte dos artistas) e incorporação (por parte das instituições), muitas vezes o sentido da transgressão se transforma e o ato 
transgressivo em si é banalizado. Dessa forma, torna-se peremptória a discussão sobre a arte transgressiva e sua relação com as instituições que propõem seu agenciamento, os meios de comunicação, o consumo, o mercado artístico, o capitalismo industrial, a crítica de arte, a produção e a difusão.

Quanto ao segundo caso, deve-se considerar ainda que essas intervenções não raro são suscetíveis de contraposições, conflitos, censuras, violências e criminalizações. Os casos de obras que foram censuradas durante as ditaduras militares, ou daquelas censuradas por questões morais e/ou religiosas nos países latino-americanos são aqui exemplares. Em tempos de crise, de segregação e preconceitos, de arrogância, de guerras de poder, de intolerância e manipulação dos meios de comunicação, percebe-se que esse debate vai além de discussões sobre a liberdade de expressão ou sobre a autonomia penal da produção simbólica, uma vez que abarca questões políticas, sociais e um importante jogo de forças existente entre os atores envolvidos.

7 Todas essas implicações motivaram, inicialmente, a realização do Colóquio Internacional Transgressão nas artes/ Transgressão das artes que ocorreu na USP em 2013. O projeto foi fruto da colaboração entre a Universidade de São Paulo (Departamento de Filosofia) e a Université Paris 1 Panthéon-Sorbonne (Laboratório ACTE CNRS/ Université Paris 1 - Grupo de estudos estéticos) no que concerne ao estudo dos problemas estéticos e éticos da contemporaneidade. Coordenado por Gaspar Paz e Olgária Matos, o Colóquio, que contou com o financiamento da FAPESP, congregou pesquisadores de diferentes instituições, entre eles: Dominique Chateau, Jacinto Lageira, Lilian Santiago, Raoul Kirchmayr, Renato Janine Ribeiro, Ricardo Fabbrini e Samuel Araújo. Os questionamentos foram tão percucientes que nos impeliram a prosseguir e ampliar o debate. Nessa perspectiva, a participação da pesquisadora Aline Miklos (École des Hautes Études en Sciences Sociales) foi decisiva, tanto para o aprofundamento das questões, quanto para a organização deste número temático para a Revue Artelogie. Assim, retomando as discussões do Colóquio, começamos o dossiê com uma entrevista realizada com a filósofa e escritora Olgária Matos (USP/UNIFESP), na qual ela rediscute alguns dos principais pontos levantados no encontro. A autora discorre sobre experiências criativas, humanismo ocidental, autonomia das artes, direito à diferença, indústria cultural, cultura do ilimitado, bem como sobre a temporalidade e a arrogância no mundo capitalista.

8 Três outros textos apresentados nesta ocasião também foram publicados neste número com o intuito de redimensionar certas discussões teóricas sobre o tema em questão. 0 primeiro, do Prof. Dr. Ricardo Fabbrini e intitulado Estética e transgressão : da arte radical à arte radicante, expõe a transformação de certas tendências conflitantes do panorama estético contemporâneo, além de questionar determinados paradoxos da arte relacional. Nesse sentido, o autor contrasta as ideias de Nicolas Bourriaud, François Lyotard e Jacques Rancière ao investigar a transição do projeto moderno de estetização da vida para a disseminação do cultural na contemporaneidade. Dessa forma, interpreta a ideia de transgressão no âmago das pesquisas e críticas artísticas.

Em seguida, o Prof. Dr. Dominique Chateau - no ensaio "O artista de hoje : entre o desencantamento pós-moderno e as retomadas do engajamento. A propósito de uma exposição tunisiana" - avalia o impacto de uma exposição realizada no Palácio Abdellia de La Marsa, em Túnis, na ocasião da $10^{\mathrm{a}}$ edição da Primavera das Artes (2012). A censura pública à exposição, que alegava que certas obras feriam princípios do islã, causou polêmica. Partindo de tais circunstâncias e de uma releitura particular das 
teorias da arte, Chateau discute o papel da criação e da liberdade na expressão dos artistas. $\mathrm{O}$ autor avaliou, assim, a repercussão cultural e os valores sociais na medida em que identificou o artista como um tipo social persistente que é capaz de apresentar, no ambiente cultural, criações desestabilizadoras.

Por fim, neste primeiro bloco de textos, contamos com a participação do Prof. Dr. Raoul Kirchmayr por meio do ensaio La transgression dans l'art: vers une esthétique de la spectralité (la Nymphe de Freud). Kirchmayr interrogou o estatuto estético e epistemológico do espectro no horizonte atual, sublinhando suas características políticas, sociais e culturais. Assim, analisou a relação entre a imagem e o presente, retomando de forma singular a ideia de transgressão da ordem metafísica, a partir da célebre leitura, desenvolvida por Freud, do romance Gradiva. Une Fantaisie pompéienne de Wilhelm Jensen. Os ensaios de Dominique Chateau e de Raoul Kirchmayr, que aparecem aqui em francês e português, foram traduzidos por Cristina Moura, que durante o Colóquio (na USP) havia realizado a interpretação consecutiva das conferências de ambos os autores. Dessa forma, os textos guardam ainda um interessante caráter oral.

O segundo bloco é composto por ensaios que discutem o conceito de transgressão a partir de obras de artistas que questionam a heteronormatividade e a dicotomia entre masculino e feminino. Aqui, o corpo é visto não só como arma, mas também como palco principal para todas estas transformações. Existe feminino e masculino ? A autora Araceli Sánchez busca romper com este binômio - e com diversos outros como sagrado/ profano, puro/impuro, transgressão/escravidão - por intermédio da teoria da complexidade de Edgard Morin. Segundo Morin, a necessidade de ordenar os fenômenos do conhecimento e rechaçar toda desordem, ambiguidade e incerteza característica de qualquer fenômeno complexo é o que leva as pessoas a constituírem o seu mundo a partir de dualismos e categorias imutáveis. A consequência disto seria a produção de uma cegueira que ignora outras características desse complexo. (MORIN, $2005:^{3}$ ). A partir desta ideia, Sánchez propõe uma reflexão sobre algumas obras de artistas feministas mexicanas, como Mónica Mayer e Elizabeth Romero.

12 Talita Trizoli, em texto para esta edição, busca romper com a dicotomia masculinofeminino a partir da reflexão, de Judith Butler, sobre as identidades de gênero em performatização, segundo a qual o gênero é considerado como uma vivência e uma prática em constante metamorfose (BUTLER, 2003). Talita Trizoli, ao analisar a obra Sérgio e Simone de Virgínia de Medeiros, também se apoia em alguns autores da teoria Queer e na sagacidade de Beatriz Preciado em utilizar a ironia e a paródia como métodos de desestabilização dos sistemas de saber, justamente para apontar o caráter subversivo e transgressor da obra em relação à heteronormatividade (PRECIADO, 2014). Maria Laura Rosa, por sua vez, retoma alguns desses autores para discutir as obras de três artistas argentinos - Ilse Fusková, Liliana Maresca e Batato Barea -, realizadas logo após o fim da ditadura militar na Argentina. Aqui, o engajamento político de tais artistas faz com que suas obras e seus próprios corpos sejam instrumentos de subversão da regra heteronormativa.

13 Os quatro textos seguintes discorrem sobre o campo da arte e suas relações com a política. No artigo "El Teatro Militante: subversiones y resistencias durante la dictadura cívico-militar uruguaya (1973-1985)”, Luciana Scaraffuni analisa, com muita perspicácia, as formas de resistência das práticas teatrais uruguaias. Tais ações foram críticas à ditadura naquele país e procuraram se desfazer das dominações, coerções e mazelas que assolavam o campo cultural. Nesse sentido, os grupos independentes de 
teatro criaram espaços de diálogo, promovendo a tomada de consciência e, além disso, mobilizando manifestações em reação à violência de estado e à repressão.

Os movimentos políticos que se deflagraram a partir da verve teatral também foram marcantes em outras linguagens, como a poesia e as artes visuais. Salientando alguns desses aspectos, agora diante da realidade política brasileira dos anos 1962-1969, Marcelo Mari retoma traços importantes da trajetória do poeta e crítico Ferreira Gullar. Para tanto, o autor discute a marca da dimensão política e do engajamento para a compreensão de Ferreira Gullar sobre a crise da vanguarda brasileira e, posteriormente, para a sua própria reorientação estética. Marcelo Mari ressalta, que ao romper com a experimentação concretista, Ferreira Gullar produziu peças para teatro e poemas de cordel a fim de despertar a consciência política das classes trabalhadoras. Como se os limites da linguagem e da realidade insuflassem no autor um outro poder de transgressão. Tais constatações remontam o interesse do artista por um realismo diferente do realismo socialista, do realismo da pop art norte-americana e do nouveau réalisme francês.

15 Tendo ainda a cena brasileira dos anos 1960 e 1970 como horizonte, a pesquisadora Maria de Fátima Morethy Couto avalia o período a partir da transgressão de modelos e censuras, gerados principalmente pelos impasses da situação política e econômica do país. Por essa razão, segundo a autora, muitos artistas e intelectuais se engajaram no debate político na tentativa de propor alternativas a esse panorama hostil, marcado por uma ditadura militar. Couto aborda tais questões levando em consideração todo um itinerário histórico da política brasileira, investigando ainda como as reverberações desse contexto influenciaram artistas e críticos da época.

Numa outra forma de enfrentar o jogo político, artístico e filosófico, Débora Ferreira e Cleverson Luiz Salvaro, no artigo "Violadores do jogo : um diálogo entre Artur Barrio e Vilém Flusser", partem de uma leitura peculiar da obra "4 dias, 4 noites" (1970) de Barrio, artista luso-brasileiro, por meio da aproximação com os conceitos de "poiesis", "jogo" e "jogador", matizados por Flusser. A hipótese dos autores é que tanto as interpretações de Flusser como as experiências transgressoras de Barrio "possam se iluminar mutuamente, tornando mais claro o caráter experimental e inovador de suas obras". A produção de Barrio é um exemplo visceral que se vincula às conceituações de Flusser, pois literalmente encarna o jogo, a desterritorialização, a crítica ao produto artístico, tendo como anseio a transposição dos espaços estabelecidos e das convenções sociais. Sua atuação, que subverte cânones tradicionais, representa uma contundente leitura da realidade sociocultural latino-americana.

17 Ângela Grando, no ensaio "Sal sem carne - para uma estética do gueto" passeia pelos "circuitos ideológicos" de Cildo Meireles, ressaltando sua forma de lidar com a realidade e a utopia. Meireles possui um gesto artístico especial para lidar com a politização do estético e a estetização da política. No caso da instalação "Sal sem carne", enfocada por Grando, o artista plástico brasileiro denuncia a expropriação e o descaso com as comunidades indígenas. Tudo isso a partir de uma experiência em nada convencional, representando com intensidade, perplexidade e ação, a plasticidade e sonoridade de circunstâncias adversas.

O quarto bloco é composto por três textos que levantam uma discussão sobre a relação entre transgressão e regras da arte. É interessante observar que em cada um deles a transgressão se dá a partir de "movimentos" e "hibridizações". O texto de Lina X. Aguirre, por exemplo, ao analisar as obras de dois artistas contemporâneos chilenos, 
abre este bloco afirmando que a quebra de paradigmas da arte também ocorre em operações de transformação ou de trânsito entre meios artísticos, o que se denomina transferência. Para a autora, o uso recorrente das ferramentas digitais e da tecnologia nos permitiu modificar infinitas vezes a obra de arte, chegando a um ponto onde os diferentes meios artísticos se misturam e se sobrepõem, provocando o que a crítica de arte Rosalind Krauss denomina de "condição pós-meio" (KRAUSS, 2000).

Giuseppe Gatti Riccardi e Rafael Arce, em seus respectivos textos, analisam dois romances distintos onde a transgressão se encontra na hibridização das formas. Giuseppe Riccardi analisa o romance Para Eva (escrito na década de 1980 e publicado somente após sua morte) de Enrique Lihn, no qual ele sugere um diálogo entre a literatura e as artes plásticas, uma vez que esse escritor revela que alguns de seus romances foram inspirados em suas próprias pinturas. $\mathrm{O}$ caráter subversivo de sua obra, segundo Guiseppe Riccardi, está na "carnavalização" da ruptura com os cânones da ortodoxia estética e sexual e também no travestismo, artifício utilizado pelo autor como estratégia de criação. Rafael Arce também acredita que no romance Zama (1956), de Antonio Di Benedetto, a transgressão está na forma, já que o escrito pode ser interpretado como uma negação do romance histórico, pois transgride qualquer procedimento de verossimilhança na construção narrativa. Atento ao humor e ao grotesco em tal obra, Rafael Arce afirma que o grotesco se apresenta aí mediante o movimento constante realizado pela passagem do humano para o animal, do animal para o vegetal etc.

20 A Instituição e a crítica de arte foi o tema das reflexões de nosso último bloco. Nessa linha, Almerinda da Silva Lopez interpretou a recepção crítica da produção de Georges Mathieu no Brasil. $\mathrm{O}$ autor, que trabalhava de forma sui generis a linguagem pictórica e a ação performática, provocou polêmica ao romper com certos preceitos numa exposição no MAM do Rio de Janeiro, em 1959. Tratou-se de uma performance que congregava a pintura de uma tela abstrata de grandes dimensões, com a música e a dança afrobrasileiras. Motivados por tais ações, os críticos da época avaliaram de forma contundente os acontecimentos por meio de uma leitura da história e dos feitos artísticos no Brasil.

O conjunto de textos publicados nesse dossiê nos revela que os gestos artísticos e transgressivos, por mais que tenham tomado diversas formas e significados ao longo do tempo, continuam sendo gestos que estão voltados à ideia de limite. No entanto, esses gestos significaram muito mais que a ruptura de limites preestabelecidos. Em muitos casos aqui descritos, eles implicaram na perda de rigidez, na flexibilização e no deslocamento de regras e convenções. Por isso, se em um primeiro momento decidimos, por motivos didáticos, dividir as artes transgressivas em três tipos (a arte que ultrapassa as regras da arte, a arte que destrói os tabus e a arte de resistência política) ; num segundo momento, percebemos que todos esses tipos de transgressão se mesclam constantemente. $O$ que os une, como dissemos anteriormente, é o princípio de contestação e a necessidade de mudança.

Cabe aqui uma reserva, visto que todas essas linhas de abordagem nos remetem, de uma forma ou de outra, a enfrentamentos concretos do ato de transgredir, aludindo suas peculiaridades e observando suas modificações históricas. Algumas dessas características da transgressão são indeléveis na medida em que deixaram um legado cultural importante. Como esquecer, por exemplo, Sade demonstrando "incansavelmente a tolice, a hipocrisia e a nulidade da virtude" ? (BLANCHOT, 2010 : 
83) [3]. E quanto aos libertinos, Artaud e os surrealistas ? E se mudássemos a clave para a esteira dos trabalhos críticos e teóricos ? Por exemplo, Sigmund Freud nos dá os alicerces para pensarmos a transgressão no terreno da sexualidade e do inconsciente. A ele se sucede, articulando toda a gama dos caracteres descritos, Georges Bataille. Com o marco da obra l'Erotisme e de Documents, toda uma área de atuação se abre aos olhos dos críticos - história da arte, antropologia, arqueologia, etnografia, psicanálise, entre outros. A partir daí são várias cabeças a difundir os esforços de Bataille, a começar por Foucault, Blanchot e Georges Didi-Huberman.

Os novos posicionamentos ultrapassam literalmente a impostura das instituições, a violência policial, o esvaziamento das relações sociais. E tudo isso em direção a um tempo, como diria José Américo Motta Pessanha, "marcado pela ênfase dada às noções de ruptura, de diferença, de pluralidade" (PESSANHA, 1987 : 61). Segundo Pessanha, os traços da contemporaneidade vislumbram tout court as categorias "de multiplicidade, de corte, de alteridade" (PESSANHA, 1987: 61). Com o pronunciar dessa alteridade é todo um autoritarismo social que se vê combalido, ou ao menos ultrajado. A regulação dos poderes e direitos sociais muitas vezes instaura na tarefa $d a$ lei, como salientou Marilena Chauí, "a conservação de privilégios e o exercício da repressão". (CHAUÍ, 2001 : 14) Segundo a autora, "Por esse motivo, as leis aparecem como inócuas, inúteis ou incompreensíveis, feitas para serem transgredidas e não para serem transformadas". (CHAUÍ, $2001:$ 14)

Essas são algumas das tendências adstritas ao ato de transgredir. Ao mencioná-las aqui pretendemos fazer jus as inflexões de um panorama singular. As implicações desses cenários são abrangentes e configuram uma nova consciência histórica que busca a compreensão crítica dos pressupostos estéticos e das relações sociais. Estas reflexões abrem novos caminhos para se pensar as artes latino-americanas e os seus consequentes desdobramentos, além de possibilitar um enfrentamento mais arrojado diante dos conflitos e paradoxos das expressões de nosso tempo.

\section{BIBLIOGRAFIA}

BATAILLE Georges, L'Erotisme, Paris, Les Editions de Minuit, 2001.

BATAILLE Georges, La littérature et le mal, Paris, Gallimard, 1957.

BLANCHOT Maurice, La condition critique, Articles 1945-1998, Paris, Gallimard, 2010.

BLANCHOT Maurice, Une voix venue d'ailleurs, Paris, Gallimard, 2002.

BUTLER Judith, Problemas de Gênero. Feminismo e Subversão da Identidade, Rio de Janeiro, Civilização

Brasileira, 2003.

CHAUí Marilena, Escritos sobre a universidade, São Paulo, Editora UNESP, 2001.

DIDI-HUBERMAN Georges, “Como transgredir a forma ?", in A semelhança informe : ou o gaio saber visual Segundo Georges Bataille. Tradução Caio Meira, Fernando Scheib e Marcelo Jacques de Moraes, 2015. 
FOUCAULT Michel, “Prefácio à transgressão”, in Estética: literatura e pintura, música e cinema. Organização e seleção de textos Manoel BARROS DA MOTTA. Tradução: Autran DOURADO, Rio de Janeiro, Forense Universitária, 2001.

HEINICH Nathalie, Le triple jeu de l'art contemporain, Paris, Les Éditions de Minuit, 2006.

KRAUSS R.E., BROODTHAERS M., A Voyage on the North Sea: Art in the Age of the Post-medium Condition, New York, Thames \& Hudson, 2000.

MORIN Edgar, Introducción al pensamiento complejo, Barcelona, Gedisa, 2005.

NOVAES Adauto (org.), Libertinos e libertários, São Paulo, Companhia das letras, 1996.

PESSANHA José Américo Motta, "Cultura como ruptura", in Tradição e contradição, Rio de Janeiro, Jorge Zahar editora/ Funarte, 1987.

PRECIADO Beatriz Paul, Manifesto Contrasexual. Práticas subversivas de identidade sexual, São Paulo/ Helsinki, N-1 edições, 2014.

STALYBRASS Peter e WHITE Allon, The politic and poetics of transgression, Ithaca, Cornell University Press, 1986.

\section{NOTAS}

1. Michel Foucault refere-se a esse princípio de contestação, em Blanchot, para ressaltar uma espécie de "prova do limite" (FOUCAULT, 2001: 34). Além disso, pode-se conferir a atmosfera desses posicionamentos nos próprios ensaios de Maurice Blanchot: "La condition critique", "Le discours philosophique" e "Quelques remarques sur Sade" (Blanchot, 2010).

2. Michel Foucault - no "Prefácio à transgressão" (FOUCAULT, $2001: 28$ ) - para abordar a ideia de sexualidade enfatiza esses três pontos : o limite da consciência, o limite da lei e o limite da linguagem.

3. «Sade prouve inlassablement la sottise, l'hypocrisie et la nullité de la vertu " (BLANCHOT, $2010: 83)$

\section{RESUMOS}

São representativas na história da arte latino-americana as tensões entre a norma e a contravenção, a moralidade e a imoralidade, o clássico e o popular, o oficial e o extraoficial, o Novo e o Velho Mundo. Neste jogo de forças, observamos que a transgressão emerge de uma espécie de saturação diante de situações-limite, visto que a ação de transgredir põe em cena o extravasamento das relações, seja mediante um ímpeto novo de imaginação e criatividade, seja pela suspensão dos acontecimentos. Assim, a ideia de transgressão pode ser considerada como impulso de transformação em situações variadas, já que reacende o espírito crítico através daquilo que Blanchot chamou de princípio de contestaçãoi e que se define como um esforço de pensar e agir de um modo outro. 
AUTORES

GASPAR PAZ

UFES

ALINE MIKLOS

(CRAL-EHESS)

OLGÁRIA MATOS

(USP)

DOMINIQUE CHATEAU

(Paris 1-Sorbonne) 